\title{
Hard coal preparation in a single stage crushing circuit for gasification purposes
}

\author{
Bartlomiej Ryszka ${ }^{1, a}$, and Daniel Saramak ${ }^{1}$ \\ ${ }^{1}$ AGH, University of Science and Technology, Faculty of Mining and Geoengineering, Department of Mineral \\ Processing and Environmental Engineering
}

\begin{abstract}
The article concerned the problem of coal preparation for gasification purposes. The main aim was to design the coal crushing circuit, which would produce the material within the particle size range between 0.5 and $5 \mathrm{~mm}$. The one-stage crushing circuit based on hammer crusher was proposed. There laboratory tests of coal crushing in two circuits: one-stage circuit based on a hammer crusher and two-stage circuit based on jaw and roller crushers were also performed. The results showed that application of the one-stage circuit appeared to be more favorable both in terms of energy consumption and, if considered, the product particle size.
\end{abstract}

\section{Introduction}

In a gasification process, coal treated with oxidizing agent is being transformed from the fossil fuel into the gas fuel, and it takes place in an installation with a dedicated gasification reactor as a main device. The technology is consistent with current world energy policy, which focuses on development of clean coal technologies with low $\mathrm{CO}_{2}$ emission and low waste production. Petrographic diversity of coal generates a justified need of application of suitable technological processes that would precede the main gasification operation [1]. The primary objective of these preparatory processes is to achieve for coal certain parameters, which are needed in order to meet requirements of a applied gasification reactor type. Proper coal preparation is one of the main factors that determine possibility of conducting stable and consistent oxidation reaction. This is the reason of mineral engineering being first and important part of gasification technology. Depending on the reactor type, parameters required for coal processing are different for each technology and this paper focuses on coal feeded for gasification in circulating fluidized bed (CFB) reactors [2]. In this work the required specifications of coal and possible methods of their achievement through application of mineral processing methods with the lowest possible energy consumption and simplicity of proposed technological solutions will be presented.

Conversion of coal from fossil fuel into a gas, during gasification, takes part due to the influence of the oxidizing agent, which can be a steam, $\mathrm{O}_{2}$ or $\mathrm{CO}_{2}$. The main idea consists of injecting coal into a reactor and treating it with hot stream of reaction gas at the same time, allowing coal particles to be lifted by that stream and creating dynamic suspension in reactor chamber. This phenomenon is called fluidization. The coal residence time in the reactor chamber is between 10 to 100 seconds and

${ }^{\text {a }}$ Corresponding author: dsaramak@agh.edu.pl 
temperature oscillates around $800-1050{ }^{\circ} \mathrm{C}$. Such temperature does not guarantee full coal oxidization, however, conducting the process in higher temperature could cause unwanted coal slagging. In order to achieve full coal conversion into gas, coal has to undergo a regasification process. As a final result, the gas obtained in that process consists of $17 \% \mathrm{H}_{2}, 53 \% \mathrm{CO}, 15 \% \mathrm{CO}_{2}$, $10 \% \mathrm{H}_{2} \mathrm{O}, 2 \% \mathrm{CH}_{4}$.

The results of oxidization process are connected with the physical and chemical properties of coal feed, such as the reactivity, particle size, ash content, calorific value coking properties as well as chlorine and sulfur content [3]. The typical values of these parameters are presented in Table 1.

Table 1. Required coal parameters for CFB reactor.

\begin{tabular}{|c|c|}
\hline Type of parameter & Value required \\
\hline Reactivity & High \\
\hline Particle size, $\mathrm{mm}$ & $0.5-5$ \\
\hline Ash content & Unlimited \\
\hline Ash melting temperature, ${ }^{\circ} \mathrm{C}$ & $>1100$ \\
\hline Moisture content, $\%$ & $<5$ \\
\hline
\end{tabular}

The other issue is a technological process of coal preparation for gasification purposes. It is necessary to optimize the technological circuit in terms of energy and effectiveness, considering the fact that the gasification process itself generates the costs, which in overall assessment of this technology might indicate that gasification is the process with rather low possible benefits.

\section{Methodology and results}

The main aim of this paper is to present an approach to design the crushing circuit, which may result in lower processing costs, and as a result it may increase possible benefits of application of the gasification process, especially in terms of energy consumption [4-5]. The suitable circuit of coal processing was designed, which the primary purpose was to achieve the coal particle size from 0.5 to $5 \mathrm{~mm}$. Application of one crushing stage demands an application of a hammer impact crusher the device capable to achieve a high comminution degree (Sx) up to 30. Application of this crushing device type has also many other significant advantages. It has ability of adjusting to variable feed parameters with replaceable grid (installed grid defines the output mesh size), hammers and impact plates and also possibility of changing the rotor speed. All these features guarantee the device responsiveness and a fixed particles size distribution, even if feed parameters change in time. The hammer crusher, especially the one working in the closed circuit, also provides high cubicity of its products, which results in greater surface area, and thus higher coal reactivity.

To confirm the accuracy of hammer crusher application into the coal preparation circuit for gasification purposes, suitable tests in the laboratory scale were performed. Two types of crushing circuits were tested: first one as a two-stage with the jaw crusher operated in the closed circuit, followed by the roller crusher, and the second one, as a one-stage, with the hammer crusher. The feed material particle size was the same for both circuits and ranged from 5 to $31.5 \mathrm{~mm}$. The jaw crusher in the first circuit has operated with the gap value $5 \mathrm{~mm}$, while the gap in the downstream roller crusher was $4 \mathrm{~mm}$. The jaw crusher product below $5 \mathrm{~mm}$, was the final product. The hammer crusher operated with a grid $10 \mathrm{~mm}$. The test results were analyzed in terms of productivity the product below $5 \mathrm{~mm}$, and from the energetic point of view. The results are presented in Table 2 .

The results of laboratory scale investigations show that application of the single crushing stage results in greater yield of particle size fraction $0-5 \mathrm{~mm}$, which was $95 \%$, while the two-stage crushing circuit results in only $65 \%$. Furthermore, the one-stage crushing circuit is more favorable also in terms of energy consumption with minor energy demand per $1 \mathrm{Mg}$ of crushed material. 
Table 2. Results of laboratory tests.

\begin{tabular}{|c|c|c|}
\hline Parameter under investigation & One-stage circuit & Two-stage circuit \\
\hline Energy consumption $\left(E_{\mathrm{sp}}\right), \mathrm{MJ} / \mathrm{Mg}$ & 11.16 & 13.86 \\
\hline Yield of product below $5 \mathrm{~mm}\left(\gamma_{-5}\right), \%$ & 95 & 65 \\
\hline
\end{tabular}

\section{Summary}

Coal gasification processes are becoming more important, especially from the scope of increasing energy demands together with technological development of the world. On the other hand, it is necessary to find a proper selection of coal preparation circuit, in order to achieve the required effectiveness of its work.

The results of investigations presented in this paper show that application of a hammer crusher gives more favourable results both in production of the required size of product and in terms of energy consumption. These two factors are the most significant in the presented case and the obtained results prove that application of one-stage crushing is justified both from technological and economic point of view. Moreover, it guarantees process stability, simplicity of its course, and also lower investments cost, resulting from smaller number of the required devices.

\section{References}

1. D. Krawczykowski, J. Marciniak-Kowalska, A. Surowiak, Pol. J. Environ. Stud., 22, 6 (2013)

2. T. Chmielniak, M. Sciazko, A. Sobolewsk, Karbo, 1 (2012)

3. J. Marciniak-Kowalska, T. Niedoba, A. Surowiak, T. Tumidajski, Arch. of Min. Sci., 59, 3 (2014)

4. T. Gawenda, AGH J. of Min. Geoeng., 4 (2010)

5. T. Gawenda, AGH J. of Min. Geoeng., 2 (2011) 